\title{
Deputados brasileiros no Twitter:
}

um estudo quantitativo dos padrões de adoção e uso da ferramenta

Brazilian deputies on Twitter: a quantitative approach

\section{Representantes políticos no Twitter: entre os valores democráticos e a construção da imagem pública}

Não há como negar que o Twitter tem se revelado um dos instrumentos de comunicação contemporâneos que mais chamam a atenção de jornalistas, celebridades do show business e de usuários comuns. ${ }^{1} \mathrm{~A}$ crescente utilização da ferramenta, que já conta com mais de 200 milhões de usuários ativos por mês, deve-se, dentre outros fatores, (1) ao fato de ela se constituir um recurso de comunicação rápido e conveniente; (2) à oportunidade que oferece de se preencher o tempo livre disponível em situações cotidianas (acessando conteúdos ou interagindo) (Williams e Gulati, 2010); e, a depender da extensão da rede de contatos de cada usuário, (3) ao potencial de se alcançar diretamente uma variedade de seguidores ${ }^{2}$.

\footnotetext{
É professor do Instituto de Cultura e Arte da Universidade Federal do Ceará (Fortaleza, CE, Brasil). E-mail: marquesjamil@yahoo.com.br.

** É professor do Departamento de Ciências Sociais da Universidade Federal do Ceará (Fortaleza, CE, Brasil).E-mail: jaa@ufc.br.

*** É professora do Departamento de Comunicação da Universidade Federal de Sergipe (Aracaju, SE, Brasil).E-mail: ednamiola@gmail.com.

Os autores são gratos a Camila Mont'Alverne e a Fernando Wisse pela colaboração no levantamento de parte dos dados examinados neste artigo. A pesquisa contou com financiamento oriundo do Edital MCT/CNPq/MEC/CAPES (processos 401062/2010-4 e 485320/2012-6).

2 De acordo com o administrador da plataforma (Twitter, 2012). Segundo o relatório do Pew Research Center's Internet \& American Life Project, o número de norte-americanos usuários de redes sociais digitais saltou de 8\% em fevereiro de 2005 para 72\% em maio de 2013. Especificamente acerca da utilização
} 
No que se refere à dimensão política do microblog, ressalte-se que, de acordo com o relatório World Leaders on Twitter (Digitaldaya, 2012), 123 chefes de Estado de todo o mundo estavam registrados na referida rede social em dezembro de 2012, fosse por meio de um perfil próprio ou através de um perfil oficial do cargo ocupado. Isso significa que cerca de $75 \%$ de todas as principais lideranças políticas nacionais (muitas delas, inclusive, oriundas de países não democráticos) adotaram o Twitter enquanto canal de comunicação.

A tabela 1 apresenta uma lista dos dez líderes mais proeminentes quanto ao número de seguidores no Twitter. A quantidade de usuários interessados no que os chefes de Estado têm a dizer e o número de mensagens publicadas por eles permitem verificar a importância que tais autoridades conferem à ferramenta, por mais que os efeitos causados pela utilização desse recurso (no que se refere, por exemplo, ao processo de produção da decisão política) sejam alvo de controvérsias.

Tabela 1. Lista dos 10 chefes de Estado com maior quantidade de seguidores no Twitter

\begin{tabular}{|c|c|c|c|c|c|c|}
\hline Nome & País & Endereço & $\begin{array}{l}\text { Número de } \\
\text { seguidores }\end{array}$ & $\begin{array}{l}\text { Número de } \\
\text { seguidos }\end{array}$ & $\begin{array}{l}\text { Quantidade } \\
\text { de tweets }\end{array}$ & $\begin{array}{c}\text { Data de criação } \\
\text { da conta }\end{array}$ \\
\hline Barack Obama & EUA & @Barack0bama & 26.757 .305 & 666.325 & 8.426 & $05 / 03 / 2007$ \\
\hline Hugo Chávez & Venezuela & @chavezcandanga & 3.944 .117 & 23 & 1.821 & $01 / 04 / 2010$ \\
\hline Abdullah Gül & Turquia & @cbabdullahgul & 2.778 .312 & 2 & 1.000 & $09 / 12 / 2009$ \\
\hline Rainha Rania & Jordânia & @QueenRania & 2.559 .105 & 213 & 874 & $29 / 04 / 2009$ \\
\hline $\begin{array}{c}\text { Dmitry } \\
\text { Medvedev }\end{array}$ & Rússia & @MedvedevRussia & 1.921 .505 & 58 & 669 & 09/06/2010 \\
\hline Dilma Rousseff & Brasil & @dilmabr & 1.777 .513 & 574 & 393 & $10 / 04 / 2010$ \\
\hline Cristina Kirchner & Argentina & @CFKArgentina & 1.580 .610 & 50 & 2.288 & $30 / 04 / 2010$ \\
\hline $\begin{array}{c}\text { Juan Manuel } \\
\text { Santos } \\
\end{array}$ & Colômbia & @JuanManSantos & 1.579 .068 & 5.978 & 4.100 & $11 / 08 / 2009$ \\
\hline Enrique Peña & México & $@$ EPN & 1.547 .559 & 137 & 1.810 & 29/03/2007 \\
\hline $\begin{array}{c}\text { Sheikh } \\
\text { Mohammed }\end{array}$ & $\begin{array}{c}\text { Emirados } \\
\text { Árabes } \\
\text { Unidos }\end{array}$ & @HHShkMohd & 1.478 .579 & 58 & 1.304 & $03 / 06 / 2009$ \\
\hline
\end{tabular}

Fonte: Digitaldaya (2012), com atualização dos dados feita pelos autores em 2 de fevereiro de 2013.

do Twitter, o crescimento partiu de 8\% em novembro de 2010 para 18\% em maio de 2013 (Brenner e Smith, 2013). 
Um conjunto de autores defende que o diferencial trazido pelas chamadas "redes sociais digitais" (Twitter, Facebook, YouTube, dentre outras) se referiria à possibilidade de prover aos cidadãos acesso direto - e em tempo real - ao que dizem os representantes políticos ${ }^{3}$ (Gueorguieva, 2008; Gomes et al., 2009; Gulati e Williams, 2013; Lilleker e Vedel, 2013; Marques et al., 2013). Ao permitir um acompanhamento mais eficiente do exercício da representação política, o Twitter fomentaria "a habilidade dos cidadãos de fiscalizar as atividades das instituições, [o que] é crucial para qualquer sistema democrático e fundamental para construir confiança no processo político" (Smith, 2009, p. 25).

Quase a metade dos cidadãos em idade de votar já tentou contatar seus representantes no Congresso (Goldschmidt \& Ochrieter, 2008). [...] A intimidade do Twitter pode ser uma solução para que os cidadãos se sintam pessoalmente conectados aos seus representantes. Uma vantagem que emerge do uso do Twitter por parlamentares é o potencial para fortalecer a comunicação direta com os eleitores (Golbeck et al., 2010, p. 1619).

Nesse cenário, Andy Williamson (2009), particularmente, identifica quatro fatores que podem levar os parlamentares a utilizar as redes sociais digitais: pressões organizacionais (por parte das agremiações partidárias), aspectos relacionados ao ativismo (no caso de representantes engajados na defesa de causas específicas), necessidade de ampliar os instrumentos de campanha eleitoral ou, simplesmente, para se fazer presente em um ambiente que continuamente ganha popularidade. Lilleker e Jackson (2009), por sua vez, argumentam que haveria outras duas principais explicações para a utilização do microblog no caso dos membros do Parlamento no Reino Unido: oferecer serviços aos seus constituents e mostrar aos seguidores um lado "humano", tornando públicos, por exemplo, gostos musicais e esportivos ou, mesmo, fazendo piadas alheias ao mundo político.

Já em 1987, Arterton havia refletido sobre como o progresso tecnológico na área da comunicação poderia diminuir barreiras tradicionais impostas a uma participação mais ampliada dos cidadãos, tais como a influência dos burocratas e dos lobistas. Ao mesmo tempo, o autor também considerava que a conveniência trazida pelos media eletrônicos faria com que os representantes tivessem maior disposição em responder às demandas de seus eleitores, ainda que, na época, os mandatários já elaborassem estratégias que os livrariam do dilúvio de mensagens endereçadas aos seus gabinetes (Arterton, 1987). 
Em complemento ao que diagnostica parte da literatura, pode-se dizer, também, que a perspectiva instrumental de uso do Twitter contempla a necessidade dos parlamentares de identificar, dentre os usuários, tendências de opiniões; isso permite a eles checar as ideias que pretendem defender, por exemplo, em plenário (Congressional, 2007).

A fim de desempenhar seja qual for o papel que escolheu, o parlamentar deve se comunicar com públicos chave, tais como colegas de partido, outros parlamentares, os media, grupos de pressão, eleitores e público em geral. Tal comunicação pode se dar na forma de diálogo, o qual incentiva a resposta do interlocutor, ou de monólogo, no qual os receptores da mensagem são tidos como passivos. Na realidade, os parlamentares provavelmente usam uma mistura das duas abordagens (Lilleker e Jackson, 2009, p. 5).

Contudo, ainda que boa parte das pesquisas conduzidas na área de internet e política ao longo dos últimos anos enfatize o sucesso e as limitações das experiências dedicadas a incrementar valores democráticos (como a participação, a transparência e o fortalecimento de direitos), uma lição que se pode tirar dos estudos realizados até o momento é a de que o Twitter tem servido, de forma incisiva, como elemento que colabora na construção de imagens públicas (Aragón et al., 2012; Conway et al., 2012). Em outras palavras, na maior parte das vezes, é a ênfase no "marketing pessoal" - e não no engajamento dos usuários - que levaria os representantes a assumir o risco de se expor no Twitter.

Mas há outros aspectos que concorrem para uma utilização mais ousada do microblog por parte dos parlamentares: além da disponibilidade e do custo da conexão à internet (que influenciam o grau de adoção da ferramenta por parte dos cidadãos), da intimidade do representante com os recursos de comunicação digital e da necessidade de alcançar uma constituency de maior dimensão, deve-se observar o momento político que está sendo vivido (ou seja, verifica-se que o período eleitoral altera as disposições frente aos canais de comunicação) (Pole e Xenos, 2011; Hargittai e Litt, 2012).

É verdade que, se pudessem escolher, os congressistas pautariam sua estratégia de comunicação digital levando em conta apenas o relacionamento com seus possíveis eleitores. Alguns parlamentares norte-americanos, inclusive provavelmente por conta do voto distrital e para evitar sobrecarga -, aconselham os usuários que visitam seus websites a procurar diretamente os representantes de seus distritos (Glassman et al., 2012; Marques, 2008; Maia et al., 2011). 
A questão a ser considerada, agora, é que a política de imagem do representante não mais se restringe à constituency que o elegeu. A relatoria de uma Comissão Parlamentar de Inquérito ou a ocupação de um cargo de liderança no Congresso acabam conferindo um lugar de destaque ao deputado (o que também o faz ser mais vigiado pela imprensa e pela opinião pública), que alcança, independentemente de sua vontade, um público maior do que aquele composto por cidadãos a quem presta contas eleitoralmente (Gomes, 2009; Miguel e Biroli, 2010).

Isto é, se, por um lado, o acompanhamento cotidiano de deputados que utilizam o Twitter permite perceber que tal ferramenta tem sido empregada para conformar grupos de apoiadores a determinados projetos e causas, por outro lado, há indícios de que os agentes do campo político estão sujeitos à crítica permanente e à possibilidade de serem mal compreendidos em seu discurso. Um tweet redigido de maneira infeliz em um momento delicado reverbera na cobertura da imprensa, repercute junto aos cidadãos e pode afetar mesmo peculiaridades daquelas negociações políticas que fazem questão de permanecer fora da visibilidade pública (Gomes, 2004).

Partido da premissa de que a adoção de um canal de comunicação específico se dá a partir de uma decisão individual do representante (orientado por seus assessores, naturalmente), pretende-se investigar, neste artigo, quais são os principais fatores que motivam a adoção e o uso do Twitter por parte dos deputados federais brasileiros com atuação na 54 ${ }^{\mathrm{a}}$ Legislatura (2011-2014). O presente trabalho complementa o argumento elaborado inicialmente no texto "Parlamentares, representação política e redes sociais digitais: perfis de uso do Twitter na Câmara dos Deputados" (Marques et al., 2014).

Nos dois trabalhos, a análise dos aspectos que contribuem para a adoção e para o uso do Twitter levou em conta: (1) fatores ligados às características individuais dos parlamentares; (2) indicadores relacionados ao sistema político brasileiro; e (3) dados acerca do desempenho eleitoral e das características demográficas da constituency que elegeu o deputado.

A diferença entre os textos se dá no conjunto de variáveis consideradas. No artigo anterior, as seguintes variáveis foram examinadas em detalhes:

a) Variáveis dependentes: (1) tuitagem (média de tweets que o deputado publica semanalmente); e (2) número de seguidores. Sabe-se que a quantidade de seguidores de cada usuário varia, dentre outros fatores, de 
acordo com o interesse alheio no que ele tem a dizer. $\mathrm{O}$ interesse de qualquer parlamentar é obter a máxima quantidade de seguidores para que as mensagens que publica alcancem um público mais amplo - daí a escolha de tais variáveis. A quantidade de tweets de cada parlamentar e a evolução do número de seus seguidores foram obtidas a partir do software de estatística $\mathrm{R}$, operado semanalmente a fim de permitir um acompanhamento sistemático dos $\operatorname{dados}^{4}$ (R Core Team, 2014);

b) Variáveis independentes: (1) sexo do parlamentar; (2) idade; (3) cargos de liderança exercidos na Casa; (4) número de votos recebidos na Eleição 2010; e (5) características do eleitorado ${ }^{5}$. As seguintes bases de dados ofereceram informações fundamentais acerca desse item: site da Câmara dos Deputados e do Tribunal Superior Eleitoral; Censo 2010, conduzido pelo IBGE.

Os resultados da análise multivariada apresentada no primeiro texto revelaram que as variáveis sexo e proporção do eleitorado residindo em zona urbana não foram relevantes para predizer a média de tuitagem ou o número de seguidores (Marques et al., 2014). A fim de aprimorar o poder explicativo da investigação então conduzida, duas providências foram tomadas no trabalho ora apresentado:

a) Às variáveis relevantes identificadas no artigo anterior (idade; cargos de liderança exercidos na Casa; número de votos; e duas características do eleitorado, renda média e proporção com escolaridade superior) foram agregadas as seguintes: tempo de uso do Twitter; quantidade de legislaturas do deputado; ideologia partidária ${ }^{6}$;

b) Ampliou-se o recorte temporal concernente aos dados dos parlamentares: enquanto na primeira pesquisa o período considerado foi de 23 de

Os dados e os scripts necessários para replicar os resultados deste artigo estão disponíveis em: http:// www.lepem.ufc.br/dados/TwitterParlamentar.

A variável característica do eleitorado foi elaborada pelos autores e consiste do seguinte: as variáveis referentes à urbanização e à escolaridade foram construídas a partir da"proporção média da população dos municípios com idade maior do que 16 anos e menor do que 80 que morava em zona urbana e que possuía nível de instrução superior, ponderada pela Votação obtida pelo deputado nos respectivos municípios. [...] O cálculo da variável renda se deu de forma análoga, ponderando-se a renda média dos eleitores de cada deputado pela votação do candidato em cada município" (Marques et al., 2014). Outro teste realizado pelos pesquisadores relacionou as séries temporais do período coletado (antes e depois das eleições) com as diversas variáveis aqui examinadas. Esses testes não produziram resultados relevantes; portanto, a análise de séries temporais foi descartada. 
fevereiro a 5 de julho de 2012, o intervalo a que se refere a presente análise vai de 23 de fevereiro de 2012 a 14 de fevereiro de 2013.

Ao adicionar novas variáveis, a intenção é compreender: em que medida a "idade" da conta do Twitter do parlamentar influencia seu número de seguidores ou sua média semanal de publicação de tweets? É possível identificar correlações entre o número de mensagens publicadas, bem como a quantidade de seguidores, e a quantidade de legislaturas do deputado? Existe alguma correspondência entre o uso do Twitter e os partidos aos quais os parlamentares estão filiados?

Sublinhe-se que o corpus empírico em Marques et al. (2014) se referia às 463 contas de Twitter dos deputados federais brasileiros. Para o presente artigo, são estudados 457 perfis, visto que, no intervalo entre fevereiro de 2012 e fevereiro de 2013, alguns congressistas deixaram de usar o Twitter ou "mudaram de endereço", dificultando a coleta dos dados.

Para se ter ideia da dimensão do uso da ferramenta ao longo do período, informa-se que a soma de todos os tweets postados em um pelos 457 deputados que compõem a base de dados chegou a 504.827 (quando são incluídos os períodos não cobertos pelo recorte analítico aqui proposto, a quantidade de tweets por esses mesmos indivíduos chega a 1.680.111). A soma de todos os seguidores no último dia de coleta, por sua vez, alcançou 3.175 .782 usuários ${ }^{7}$.

\section{Análise empírica}

Em certa medida, pode-se dizer que este estudo encontra um paralelo na pesquisa de Williams e Gulati (2010). Tais autores selecionaram três grupos de variáveis para explicar o uso do Twitter por congressistas nos Estados Unidos: (1) os atributos demográficos dos círculos eleitorais (educação, etnia, idade e urbanização), correlacionados com o acesso e uso da internet por parte dos cidadãos; (2) os atributos pertinentes para explicar o ambiente político-eleitoral (partido político, votação obtida, volume de financiamento); e (3) as características pessoais dos parlamentares (idade e visibilidade). Como é possível perceber, algumas das variáveis analisadas aqui são distintas, abrindo mão do exame de determinados aspectos e acrescentando outros, de acordo com a disponibilidade dos dados e com a pertinência para explicar a realidade local.

Naturalmente, alguns seguidores podem ter sido contados mais de uma vez pelo fato de seguirem mais de um parlamentar. 
É verdade, assim, que um conjunto relevante de trabalhos também tem se debruçado sobre as razões que levam os parlamentares a adotar as redes sociais digitais. Porém, poucos deles têm se preocupado em monitorar uma quantidade ampla de casos (aqui, são examinados os dados de cerca de $90 \%$ dos representantes eleitos para a Câmara dos Deputados) durante um intervalo razoável de tempo (o acompanhamento se deu semanalmente ao longo de um ano). Também é verdade que o desenho da investigação ora apresentada privilegia a dimensão quantitativa dos padrões de adoção do Twitter. Acredita-se, todavia, que a identificação de uma das dimensões das formas de uso do microblog abre espaço para que estudos futuros possam direcionar um esforço mais concentrado para entender qualitativamente o perfil das interações que caracteriza uma amostra da população aqui em questão.

Este tópico apresenta os resultados das análises de regressão multivariadas com coeficientes padronizados, tomando como referência duas tabelas que resumem a comparação entre as diferentes variáveis aqui examinadas. $\mathrm{Na}$ tabela 2 , a variável dependente é a média semanal de tuitagem. Já na tabela 3 , a variável dependente é o número de seguidores.

Como variáveis independentes, são verificados: (1) idade, (2) ocupação de cargos de liderança na Câmara, (3) número de votos brutos e ponderados; (4) perfil do eleitorado; (5) tempo de uso do Twitter, (6) ocupação de assento na Câmara em mais de uma legislatura e (7) ideologia partidária.

O primeiro teste realizado avaliou a correlação entre as próprias variáveis dependentes. Os estudos de Ammann (2010) sobre o uso do Twitter por candidatos ao Senado norte-americano descobriram uma relação positiva entre o número de seguidores de um candidato e a frequência com que ele publica mensagens. Os resultados de Marques et al. (2014) para essa relação contrariavam esses achados, e, no presente estudo, confirmou-se que a correlação entre as duas variáveis dependentes (tuitagem, de um lado; número de seguidores, de outro) era fraca. É justamente por isso que cada uma das variáveis dependentes aqui examinadas, ao interagir de modo singular com as variáveis independentes, demandou uma tabela explicativa própria.

As colunas T1 e T2 (“T” designa "tuitagem") presentes na tabela 2 representam dois modelos de regressão, tendo a tuitagem média como variável dependente. Os modelos T1 e T2 diferem em relação à variável utilizada para mensurar o número de votos obtidos pelos deputados: em T1, foi utilizado o número bruto de votos obtidos por cada parlamentar; já em T2, o número de 
votos foi dividido pela razão entre o total de votos para deputados federais e o número de deputados federais da unidade da federação que o parlamentar representa ${ }^{8}$ (o quociente eleitoral). Por um lado, considerando que a audiência no Twitter não se restringe aos eleitores dos parlamentares (constituency), a análise da votação bruta é relevante, pois pode estar associada ao número absoluto de potenciais seguidores de cada deputado. Por outro lado, acrescentar a análise da votação ponderada evitou distorções que a análise unicamente da quantidade bruta de votos traria para o estudo. Ou seja, comparar a quantidade de votos necessários para que um deputado seja eleito para a Câmara em estados populosos com os votos em um estado com menos habitantes deturparia a importância de cada parlamentar na unidade da federação que o elegeu.

Os dados mostram que o modelo T2 (votos ponderados) explica melhor a variação da variável dependente do que o modelo $\mathrm{T}^{9}{ }^{9}$, e, por isso, ele é usado como referência nas discussões seguintes.

Tabela 2. Sumários de regressões, tendo o logaritmo da média da tuitagem semanal variável dependente

\begin{tabular}{c|c|c}
\hline & $\mathrm{T} 1$ & $\mathrm{~T} 2$ \\
\hline Tempo de uso do Twitter & $0,234^{* * *}$ & $0,235^{* * *}$ \\
\hline Idade & $-0,157^{* * *}$ & $-0,148^{* * *}$ \\
\hline Mais de uma legislatura (sim) & $-0,160^{* * *}$ & $-0,162^{* * *}$ \\
\hline Cargo (possui) & $0,116^{* *}$ & $0,109^{*}$ \\
\hline Renda média do eleitorado & $-0,452^{* *}$ & $-0,441^{* *}$ \\
\hline Eleitorado com nível superior & $0,510^{* * *}$ & $0,517^{* * *}$ \\
\hline Ideologia partidária & $-0,226^{* * *}$ & $-0,225^{* * *}$ \\
\hline Votos & $0,100^{*}$ & \\
\hline Votos dep. / (votos UF / n. dep.) & & $0,131^{* *}$ \\
\hline $\mathrm{N}$ & 457 & 457 \\
\hline $\mathrm{R}^{2}$ ajustado & 0,218 & 0,225 \\
\hline $\mathrm{F}$ & 16,925 & 17,595 \\
\hline
\end{tabular}

${ }^{*} \mathrm{p} \leq 0,05 ;{ }^{* *} \mathrm{p} \leq 0,01 ;{ }^{* * *} \mathrm{p} \leq 0,001$.

$\overline{8}$ Equação: $V_{p}=\operatorname{Votos}_{\text {deputado }} \cdot \frac{\operatorname{Vagas}_{U F}}{\operatorname{Votos}_{U F}}$

A estatística $R^{2}$ corresponde à proporção da variação da variável dependente que pode ser explicada pelo conjunto de variáveis independentes existentes no modelo. 
Verificou-se que tempo de uso do Twitter, ocupar cargos, eleitorado com nível superior e votação relativa elevada têm impacto positivo sobre a tuitagem. A idade do parlamentar, ter mais de uma legislatura, a renda média do eleitorado e ser filiado a partido à direita do espectro ideológico têm impacto negativo. $\mathrm{O}$ conjunto de variáveis independentes utilizado no modelo T2 explica 22\% da variação no valor da tuitagem média semanal dos deputados $\left(\mathrm{R}^{2}=0,22\right)$. Ou seja, a partir dos dados de que a pesquisa dispõe, $78 \%$ da variação permanece sem explicação tomando como referência as variáveis aqui examinadas.

Assim como ocorre na tabela 2, na tabela 3 os modelos S1 e S2 (“S” designa "seguidores", isto é, a quantidade de seguidores de cada parlamentar em 14 de fevereiro de 2013) diferem em relação à variável utilizada para mensurar o número de votos obtidos pelos deputados. Novamente, a votação ponderada se mostrou estatisticamente mais significativa do que somente o número de votos brutos. Finalmente, o modelo S3 inclui somente as variáveis que se mostraram estatisticamente significativas e é o modelo utilizado como referência na discussão dos resultados.

$\mathrm{O}$ fato de ter atuado de mais de uma legislatura não se mostrou estatisticamente significativo e foi eliminado do modelo S3. O tempo de uso do Twitter tem impacto positivo estatisticamente significativo. Assim como ocorreu em Marques et al. (2014), a escolaridade do eleitorado tem impacto positivo sobre a variável dependente. A renda do eleitorado tem impacto negativo, embora com baixa significância estatística. No modelo S3, a estatística $R^{2}$ possui valor mais elevado do que no modelo T2 (tuitagem); em outras palavras, as variáveis são capazes de explicar uma proporção bem maior da variação do número de seguidores do que da tuitagem média. 
Tabela 3. Sumários de regressões, tendo o logaritmo do número de seguidores como variável dependente

\begin{tabular}{|c|c|c|c|}
\hline & S1 & S2 & S3 \\
\hline Tempo de uso do Twitter & $0,496^{* * *}$ & $0,505^{* * *}$ & $0,507^{* * *}$ \\
\hline Idade & $-0,198^{* * *}$ & $-0,181^{* * *}$ & $-0,188^{* * *}$ \\
\hline Mais de uma legislatura (sim) & $-0,017$ & $-0,025$ & \\
\hline Cargo (possui) & $0,087^{*}$ & $0,078^{*}$ & $0,075^{*}$ \\
\hline Renda média do eleitorado & $-0,180$ & $-0,167$ & \\
\hline Eleitorado com nível superior & $0,317^{*}$ & $0,343^{* *}$ & $0,183^{* * *}$ \\
\hline Ideologia partidária & $-0,147^{* * *}$ & $-0,143^{* * *}$ & $-0,144^{* * *}$ \\
\hline Votos & $0,240^{* * *}$ & & \\
\hline Votos dep. / (votos UF / n. dep.) & & $0,254^{* * *}$ & $0,257^{* * *}$ \\
\hline $\mathrm{N}$ & 457 & 457 & 457 \\
\hline $\mathrm{R}^{2}$ ajustado & 0,478 & 0,485 & 0,485 \\
\hline $\mathrm{F}$ & 53,211 & 54,768 & 72,576 \\
\hline${ }^{*} \mathrm{p} \leq 0,05 ;$ & $p \leq 0,001$ & & \\
\hline
\end{tabular}

Apresenta-se, a seguir, uma breve análise de cada variável.

\section{Idade}

No estudo anterior (Marques et al., 2014), a análise da relação entre o uso do Twitter e a idade dos parlamentares se mostrou importante para explicar a média de publicações semanais (tuitagem) e também o número de seguidores. No presente estudo, permanece o mesmo tipo de correlação, ainda que a interação seja controlada por um número maior de variáveis: quanto mais jovem o deputado, maior é sua tuitagem e mais seguidores ele possui.

\section{Cargos}

No artigo prévio, o fato de determinados parlamentares desempenharem funções de liderança na Câmara dos Deputados (integrar a Mesa Diretora ou ser líder/vice-líder de partido ou bloco) resultou em uma correlação positiva moderada no que se refere à tuitagem e uma alta correlação positiva quanto ao número de seguidores. 
Na presente investigação, a ocupação de cargos de liderança continuou estatisticamente relevante, mas a situação se inverteu a partir da interação com novas variáveis. Agora, a correlação entre ocupação de cargos e a média de tuitagem aumentou, enquanto a relação entre ocupação de cargos e maior quantidade de seguidores diminuiu (ainda que ambas tenham se mostrado positivas).

Em relação à tuitagem, a variável que mais contribuiu para o aumento da significância estatística da ocupação de cargos foi a ideologia partidária. Isso ocorreu porque os deputados que possuem cargo, em média, estão ideologicamente à direita dos que não possuem cargos (figura 1a) e quem está à direita tuíta menos (tabela 2). Ao levar em consideração a ideologia, o impacto da ocupação de cargos sobre a tuitagem se torna mais claro. Em relação ao número de seguidores, a variável cuja adição mais reduziu a significância da ocupação de cargos foi o tempo de uso da ferramenta, porque quem possui cargo usa Twitter há mais tempo (figura 1b) e quem usa Twitter há mais tempo possui mais seguidores; ou seja, parte do impacto da posse de cargos apresentado no trabalho anterior se deve, na verdade, ao tempo de uso do Twitter.

Figura 1. Cargo, ideologia e tempo de uso do Twitter

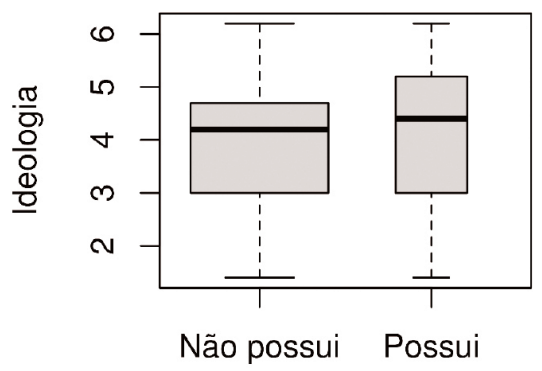

Possui cargo

(a)

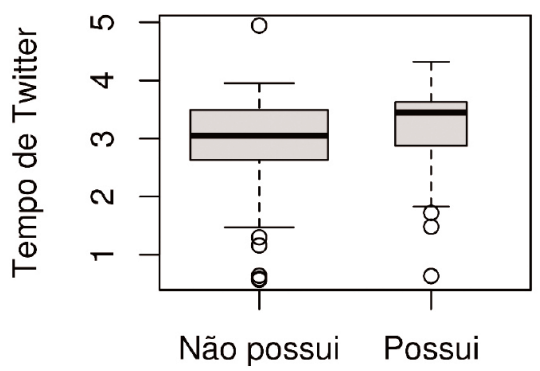

Possui cargo

(b)

\section{Votos}

O número de votos brutos de cada deputado apresentou uma correlação positiva com as duas variáveis dependentes na primeira versão da pesquisa (Marques et al., 2014). Na análise multivariada aqui executada, quando foram 
conjugadas novas variáveis àquelas já avaliadas, os resultados se mostraram diferentes: a votação bruta teve alta correlação com o número de seguidores, mas baixa associação com a tuitagem.

Um segundo teste de regressão foi efetuado utilizando a votação ponderada. Nessa análise, a variável foi examinada nas colunas T2 (tuitagem) da tabela 2 e S2 (seguidores) da tabela 3. Constatou-se que ambas as correlações estabelecidas entre votação ponderada, de um lado, e (1) tuitagem e (2) número de seguidores, de outro, são positivamente significativas. Isso implica o seguinte: quanto maior a votação proporcional do deputado no estado, maior é a probabilidade de que ele utilize com mais frequência o Twitter para publicar mensagens e de que ele também tenha mais seguidores ${ }^{10}$.

\section{Características do eleitorado}

Os resultados a respeito da relação entre o perfil dos eleitores - considerando-se (1) renda média e (2) proporção dos munícipes com escolaridade de nível superior - e o uso do Twitter por parte dos deputados, apresentados em Marques et al. (2014), pouco se alteraram quando houve interação com novas variáveis.

Anteriormente, havia se descoberto uma forte correlação negativa entre, de um lado, a renda do eleitorado municipal de cada representante e, de outro lado, as médias de tuitagem e o número de seguidores. Ou seja, quanto menor a renda da constituency de onde foram oriundos os votos do deputado, maiores foram as médias de tuitagem e o número de seguidores.

$\mathrm{Na}$ análise aqui apresentada, a variável renda do eleitorado continua predizendo a média de tuitagem (quanto menor a renda da constituency do deputado, mais ele tuíta), mas deixa de ser relevante para explicar o número de seguidores. Apesar da alta correlação entre renda e escolaridade do eleitorado, as duas variáveis têm efeito contrário sobre a tuitagem dos deputados. Se, por um lado, a renda do eleitorado for eliminada do modelo T2, ocorre uma redução na significância estatística da proporção com escolaridade de nível superior. Se eliminada a proporção com escolaridade de nível superior,

${ }^{10}$ É importante ressaltar que analisar variáveis como características do eleitorado e votos não necessariamente significa que estes pesquisadores acreditem que os deputados pretendam se dirigir apenas ao seu eleitorado. 
a renda deixa de ser estatisticamente significativa. Ou seja, o impacto da escolaridade é mais forte do que o da renda e, por isso, no modelo T2, não chega a desaparecer.

A proporção municipal de eleitores com nível superior mantém os resultados anteriores: uma proporção maior de eleitores com elevado grau de instrução é relacionada com o maior uso do Twitter e mais seguidores ${ }^{11}$.

\section{Tempo de uso da ferramenta}

A primeira das novas variáveis introduzidas neste estudo levou em consideração a data na qual cada parlamentar criou seu perfil no microblog. Verificou-se uma alta correlação positiva entre, de um lado, a variável tempo de uso do Twitter e, de outro lado, as variáveis tuitagem e número de seguidores. Percebeu-se que os deputados com o comportamento early adopter (Coleman e Spiller, 2003; Norris, 2002) acabam por apresentar uma disposição típica de heavy users: altas médias de publicações semanais e atração de mais seguidores.

\section{Mais de uma legislatura}

Foi avaliado, ainda, se o fato de determinados parlamentares terem sido eleitos mais de uma vez para a Câmara (em mandatos consecutivos ou não) pode estar relacionado ao uso que eles fazem do Twitter ${ }^{12}$. Para isso, analisou-se a variável categórica que estabelecia dois grupos: (1) os que estavam em seu primeiro mandato na Casa e (2) os que já haviam sido deputados em outras legislaturas.

Descobriu-se que, embora não haja correlação entre o número de mandatos exercidos e o número de seguidores ${ }^{13}$ (ou seja, ser deputado há seis legislaturas não implica diferença substancial em relação a

\footnotetext{
11 Naturalmente, a utilização do Twitter não é definida apenas pela quantidade de tweets publicados por parte de determinado usuário ou pela quantidade de seguidores que ele tem. É possível fazer o registro na conta e, sem se manifestar, acompanhar tudo o que está acontecendo de maneira cuidadosa, aproveitando-se das informações disponíveis no ambiente.

12 Na 54a Legislatura, há 197 deputados em seu primeiro mandato, 130 exercem sua segunda legislatura e 186 já foram deputados federais mais duas vezes.

${ }^{3}$ Quando utilizamos as legislaturas como variável numérica (número de legislaturas), nenhuma correlação foi estatisticamente significante. Transformando tal dado em variável categórica (mais de uma legislatura, mais de duas legislaturas e assim por diante), houve resultados significantes somente na clivagem entre os novatos e os veteranos na Câmara.
} 
um parlamentar que está na Câmara há seis legislaturas), há uma forte correlação negativa entre ser deputado federal veterano na Casa (com mais de um mandato) e as médias semanais de tuitagem. Parlamentares que estão em primeira legislatura, assim, publicam mais mensagens.

\section{Ideologia partidária}

A fim de analisar a adoção do Twitter por parte dos parlamentares quando observados os partidos, recorreu-se à classificação elaborada por Tarouco e Madeira (2012), de modo a tornar viável uma análise multivariada contendo uma clivagem em relação às agremiações. Aplicou-se uma escala que levava em conta a percepção de especialistas no que concerne ao posicionamento dos partidos brasileiros no espectro esquerda-direita (tabela 4) - nos valores próximos a 1 estariam os partidos "à esquerda" e nos valores próximos a 7 estariam aqueles considerados de "direita"14.

A variável ideologia partidária demonstrou uma correlação negativa tanto para tuitagem quanto para o número de seguidores caso o parlamentar seja filiado a um partido considerado "de direita". Em outras palavras, deputados de partidos mais “à esquerda” na percepção do público tendem a tuitar mais e a ter mais seguidores, enquanto os parlamentares de partidos à direita na escala tendem a publicar menor número de tweets e a ter menos seguidores.

\footnotetext{
${ }^{4}$ Sabe-se que há uma série de complicações metodológicas testemunhadas nas tentativas de se classificar, por meio de escala numérica, o gradiente ideológico de partidos políticos e de seus integrantes. As peculiaridades da cultura política de cada democracia, por exemplo, são um dos fatores que podem comprometer a consistência das medidas empregadas para se saber que agremiação está mais "à esquerda" ou mais "à direita". Não obstante empregar a escala proposta por Tarouco e Madeira, o presente trabalho não desconhece a polêmica sobre o assunto, que é discutida, por exemplo, por Luis Felipe Miguel, quando afirma que "... qualquer classificação dos partidos políticos brasileiros no continuum esquerda-direita deve ser entendida como uma simplificação grosseira, simplificação que, no entanto, é necessária, pois a volatilidade e a fragmentação de nosso sistema partidário exige que as legendas sejam reduzidas a um número "manejável" e a rótulos mais estáveis para que possamos estudá-lo. Mas não devemos esquecer de que se trata de um artifício metodológico, usado faute de mieux, não um dado da realidade" (Miguel, 2010, p. 34).
} 
Tabela 4. Escala de partidos no espectro esquerda-direita

\begin{tabular}{|c|c|}
\hline Partido & $\begin{array}{c}\text { Média } \\
\text { (1 = esq. e } 7=\text { dir.) }\end{array}$ \\
\hline PCO & 1,1 \\
\hline PSTU & 1,2 \\
\hline PSOL & 1,4 \\
\hline $\mathrm{PCB}$ & 1,5 \\
\hline $\mathrm{PC}$ do $\mathrm{B}$ & 2,3 \\
\hline PT & 2,9 \\
\hline PSB & 3,0 \\
\hline PDT & 3,3 \\
\hline $\mathrm{PV}$ & 3,5 \\
\hline PPS & 4,0 \\
\hline PMDB & 4,2 \\
\hline PMN & 4,4 \\
\hline PHS & 4,5 \\
\hline PSDB & 4,6 \\
\hline PT do B & 4,7 \\
\hline PTB & 5,0 \\
\hline PTC & 5,1 \\
\hline PTN & 5,1 \\
\hline PRB & 5,1 \\
\hline PSL & 5,2 \\
\hline PSC & 5,2 \\
\hline PRTB & 5,3 \\
\hline PSDC & 5,4 \\
\hline PR & 5,4 \\
\hline PRP & 5,4 \\
\hline PP & 6,0 \\
\hline DEM & 6,2 \\
\hline
\end{tabular}

Fonte: adaptado de Tarouco e Madeira (2012).

Neste tópico, a exposição dos dados concernente às variáveis dependentes e independentes privilegiou a descrição dos achados da pesquisa. Acredita-se que as reflexões oferecidas a seguir permitirão compreender os fatores que influenciam a adoção do Twitter por parte dos representantes de modo mais aprofundado. 


\section{Discussão}

Deputados com atuação mais destacada no Congresso acabam ganhando visibilidade nacional por meio do jornalismo político. A presidência ou a relatoria de CPIs, ou a ocupação de cargos de liderança dos partidos, têm como consequência a formação, na audiência, de um recall acerca da atuação de determinado representante (Gomes, 2004). Acredita-se que esse fenômeno tenha alguma influência sobre a quantidade de seguidores de cada parlamentar, que passam a ser acompanhados - e mesmo cobrados - por cidadãos de todo o país. Os dados apontam que a variável cargo exerce maior impacto sobre a tuitagem média semanal que o parlamentar publica do que sobre o número de seguidores. Uma investigação qualitativa realizada junto aos próprios parlamentares ou seus assessores permitiria compreender se isso ocorre porque os líderes se esforçam mais em gerenciar sua imagem ou porque eles são mais demandados por seus seguidores.

Constatou-se, também, uma coincidência entre a adoção precoce de uma ferramenta e o genuíno engajamento do usuário/parlamentar com ela. Esse resultado está em sintonia com o estudo de Hargittai e Litt:

O modelo da difusão de inovações propõe que o grau de adoção da inovação depende, parcialmente, de quão "compatível" esta é com o estilo de vida já estabelecido de um indivíduo (Rogers, 1995). Por exemplo, no caso de um serviço novo a exemplo do Twitter, os indivíduos que já usam serviços on-line similares estariam mais propensos a adotar o novo site de rede social do que os demais (Hargittai e Litt, 2012, p. 682).

A literatura da área já discute a relação entre formas de utilização do Twitter e quantidade de votos obtidos pelos parlamentares:

[...] candidatos de estados maiores podem, de fato, tuitar mais. Assim, uma vez que candidatos de estados maiores têm maior dificuldade de circular pelo seu estado ou de mobilizar sua base pessoalmente, eles utilizam os media sociais para organizar sua base de apoiadores. Entretanto, assim como a relação com o dinheiro, isso pode não ser substantivamente muito importante; é necessário um acréscimo de milhares de milhas [na área do estado] para predizer o aumento de uns poucos tweets (Ammann, 2010, p. 11).

Os resultados aqui encontrados no que se refere aos votos brutos corroboram os achados empíricos de Ammann, mas descobriu-se que ainda mais relevante se mostra a variável votação ponderada. 
Existia, em princípio, uma expectativa de que as estratégias de comunicação escolhidas pelos parlamentares estivessem associadas a seus posicionamentos políticos ou ideológicos. É interessante perceber como, a despeito da noção comum que define a ação individual dos parlamentares com base em interesses pessoais, ainda é possível, sob algumas condições, identificar clivagens ideológicas no comportamento político dos congressistas (como, ademais, afirmaram Figueiredo e Limongi, 2002). Verificou-se que os parlamentares de "esquerda" publicam mais tweets, o que pode denotar uma preocupação desses representantes com a administração de sua imagem pública. Ressalte-se que, por não haver ênfase qualitativa na presente análise, isso não garante que a postura de tais deputados represente maior zelo pelos valores democráticos, como, por exemplo, o estímulo à participação.

O acréscimo de variáveis de cariz político, a exemplo da ideologia e do número de legislaturas, e também da variável tempo de uso do Twitter aumentou o poder explicativo do modelo analítico proposto nesta pesquisa em relação ao que foi apresentado em Marques et al. (2014). Como pode ser observado nos valores do $\mathrm{R}^{2}$ ajustado (tabelas 2 e 3 ), o conjunto de variáveis aqui analisadas foi capaz de explicar $22 \%$ da tuitagem média semanal e de 49\% do número de seguidores de cada deputado - o dobro do alcançado no trabalho anterior (Marques et al., 2014). Em termos de metodologia quantitativa, 0,22 é um índice razoável para explicar a interação entre variáveis dependentes e independentes; já atingir 0,49 significa que as variáveis detêm um bom poder explicativo para dar conta do fenômeno em tela.

Pode-se tentar especular acerca da discrepância entre esses dois índices: enquanto a tuitagem depende da decisão e da disposição individual de 457 deputados em publicar mensagens, o número de seguidores depende da decisão individual de milhões de usuários do Twitter que resolvem seguir ou não um ou mais políticos. Quanto maior o número de pessoas, mais se anulam as tendências divergentes de personalidade e mais previsível é o resultado agregado.

Outras variáveis não examinadas certamente poderiam aumentar o poder explicativo dos modelos aqui utilizados: ainda não se sabe que contribuições poderiam trazer fatores tais como a escolaridade e a profissão dos deputados, ou a pressão exercida pela Presidência da Casa para que os 
media digitais sejam utilizados para aprimorar o relacionamento com a esfera civil (Marques, 2008).

Antes de encerrar a discussão das descobertas da investigação, é importante ponderar acerca de um conjunto de questões relevantes para o adequado dimensionamento das conclusões às quais a pesquisa chegou.

Primeiramente, deve-se perceber que a utilização das redes sociais digitais não é sinônimo de que o agente político está necessariamente inclinado a incentivar maior interatividade com a esfera civil. Na verdade, nem sempre o largo alcance oferecido pela comunicação digital é uma vantagem, mesmo para políticos, na medida em que uma mensagem pode chegar descontextualizada a cidadãos que não compreendem as peculiaridades de determinadas políticas nas mais diversas regiões do país.

Se, por um lado, o universo de análise considerado (os 457 deputados federais com conta no Twitter) é representativo, por outro lado deve-se insistir em uma análise qualitativa do conteúdo que eles publicam para ser possível, então, uma compreensão global acerca das formas de uso e dos efeitos da ferramenta aqui estudada.

Ademais, sabe-se que a classificação dos partidos em uma escala ideológica tem suas complicações (não se pode chamar o PMDB de homogêneo, e nem defender que o PSD tem uma diretriz ideológica clara, por exemplo; mas não se pode, por outro lado, negar o esforço e o rigor metodológico testemunhado em Tarouco e Madeira, 2012). Isso não impede, porém, perceber que existem peculiaridades no que se refere ao uso do Twitter por parte de deputados filiados a uma ou outra agremiação.

\section{Para concluir}

Se, ao longo das últimas décadas, surgiram tantas fontes e repositórios de informação, que diferencial os agentes políticos podem explorar a fim de se sobressair frente a seus concorrentes? A tendência é a de que representantes e candidatos à deputação política com necessidade de alcançar eleitorados mais amplos utilizem as ferramentas de comunicação digital de modo mais frequente. Tal fenômeno tem como pano de fundo a disputa pela construção e imposição de imagens públicas.

Nesse sentido, verifica-se, entre os deputados federais brasileiros, a mesma tendência percebida entre os líderes políticos em todo o mundo (Digitaldaya, 
2012): devem-se ocupar os espaços disponíveis nas redes sociais digitais a fim de alcançar uma maior parcela de audiência.

De acordo com parte relevante da literatura, dentre as razões que levam os representantes políticos a adotar e utilizar o Twitter (assim como outras redes) estão: a necessidade de fortalecer os mecanismos de participação, transparência e accountability; a possibilidade de se estabelecer uma comunicação direta com o cidadão; e, claro, a oportunidade de promover imagens públicas.

Assim sendo, defende-se que há variáveis que podem explicar, em certa medida, as motivações que levam os representantes a adotar os recursos de comunicação disponíveis, bem como os padrões de uso cotidiano dessas ferramentas. O trabalho de pesquisa ora apresentado teve o objetivo de colaborar com a compreensão desses gradientes.

Dando continuidade à pesquisa empreendida em Marques et al. (2014), e com o intuito de aumentar a capacidade explicativa das categorias examinadas nas análises multivariadas, foram selecionadas, coletadas e estudadas outras variáveis que acabaram por determinar uma parcela expressiva das razões que levam os representantes a utilizarem o Twitter. Conforme se pôde perceber, algumas variáveis são estatisticamente significativas para explicar a quantidade de seguidores, mas não têm a mesma capacidade de explicar a tuitagem, ou vice-versa.

Ao se analisar quantitativamente a relação entre o uso do Twitter e certas características particulares dos representantes, é possível traçar o seguinte perfil: um parlamentar relativamente jovem, mas com alta votação, que possa ser considerado um early adopter em relação às ferramentas de comunicação digital e integrante de um partido de esquerda é o que apresenta o perfil de uso mais intenso do Twitter.

Antes de encerrar o trabalho, considera-se por bem apresentar um conjunto de questões tangencialmente relacionadas à pesquisa empreendida pelos investigadores. Tais ponderações podem funcionar como especulações que guiarão a condução de novos trabalhos na área. Dessa forma, afirma-se que os estudos realizados ao longo do período compreendido entre 2011 e 2013 permitiram apontar indícios no seguinte sentido:

a) As ferramentas de comunicação disponíveis não estão "soltas" no tempo e no espaço; ou seja, seu progresso é guiado por determinados tipos de pressão exercidos por agentes de diferentes naturezas (de usuários a consultores de campanha); 
b) O grau de adoção da ferramenta por parte dos agentes do campo político acaba influenciando o próprio emprego da plataforma por parte dos usuários. Ou seja, se o representante utiliza a ferramenta de maneira limitada (com baixa frequência, por exemplo), os demais usuários tendem a se acostumar a tal modo de abordar o recurso em questão (ainda que alguns não se conformem e insistam, por exemplo, em mencionar o perfil, mesmo sabendo que dificilmente obterão resposta, como é o caso de @dilmabr, que, sem atualização entre novembro de 2010 e setembro de 2013, ganhava uma média de 400 novos seguidores por dia; ver Presidente, 2013). Já se as atualizações são constantes, justamente por perceberem que o agente terá maiores chances de ler ou de se manifestar sobre uma crítica, sugestão ou comentário, é que os usuários tenderão a se acostumar com a presença on-line da figura pública;

c) A utilização de diferentes plataformas de comunicação se relaciona intimamente à exposição que determinado agente público obtém do jornalismo. Ter muitos seguidores ou ser mencionado com frequência nas redes sociais acaba refletindo a exposição obtida a partir de fontes (desde personalidades que endossam ou criticam algo que um representante diga) e acontecimentos diversos (escândalos de corrupção em que o parlamentar está envolvido). Isso não significa, naturalmente, que esse agente utilize a rede continuamente para se manifestar (aliás, ele pode aparecer apenas quando a situação se mostrar conveniente).

Atente-se, aliás, para o fato de que a análise da atividade representativa precisa levar em conta outros elementos que se encontram para além das estratégias de comunicação. A agenda da constituency e do partido do deputado, bem como seus interesses próprios, são aspectos que compõem o perfil do mandato e, naturalmente, as expectativas quanto às formas de exposição nos media.

Por último, é verdade que o presente estudo tem, dentre suas limitações, o fato de privilegiar a dimensão quantitativa acerca da utilização do Twitter. Um aprofundamento da pesquisa, direcionando-se o foco para análise de conteúdo do tweets, permitiria compreender, por exemplo, o grau de disposição de cada parlamentar em interagir com outros usuários, bem como identificar o teor de tal conversação.

\section{Referências}

AMMANN, Sky L. (2010). "Why do they tweet? The use of Twitter by U.S. Senate candidates in 2010”. Disponível em: http://papers.ssrn.com/sol3/ 
papers.cfm?abstract_id=1725477. Acessado em 10 out. 2012. ARAGÓN, Pablo et al. (2012). “Tweeting the campaign: evaluation of the strategies performed by Spanish political parties on Twitter for the 2011 National Elections". Trabalho apresentado nas Internet, Policy \& Politics Conferences: Big Data, Big Challenges?. Barcelona, 20 e 21 de setembro. Disponível em: http://ipp.oii.ox.ac.uk/sites/ipp.oii.ox.ac.uk/ files/documents/aragon_et_al_0.pdf. Acessado em 15 set. 2013.

ARTERTON, F. Christopher (1987). Teledemocracy: can technology protect democracy?. Newbury Park: Sage.

BRENNER, Joanna \& SMITH, Aaron (2013). 72\% of online adults are social networking site users. Washington: Pew Research Center. Disponível em: http://www.senioragency.be/wp-content/uploads/2013/08/SOCIALMEDIA-WITH-ADULTS.pdf. Acessado em 30 abr. 2104.

COLEMAN, Stephen \& SPILLER, Josephine (2003). "Exploring new media effects on representative democracy". The Journal of Legislative Studies, v. 9, n. 3, p. 1-16.

CONGRESSIONAL MANAGEMENT FOUNDATION (2007). Communicating with Congress: how Capitol Hill is coping with the surge in citizen advocacy. Disponível em: http://www.congressfoundation.org/storage/ documents/CMF_Pubs/cwc_capitolhillcoping.pdf. Acessado em 10 out. 2013.

CONWAY, Bethany Anne; KENSKI, Kate \& WANG, Di (2013). “Twitter use by Presidential primary candidates during the 2012 campaign". American Behavioral Scientist, v. 57, n. 11, p. 1596-1610.

DIGITALDAYA (2012). World leaders on Twitter. Disponível em: http://www. digitaldaya.com/admin/modulos/galeria/epapers/69/epaper/ePetetion. pdf. Acessado em 02 jul. 2013.

FIGUEIREDO, Argelina Cheibub \& LIMONGI, Fernando (2002). "Incentivos eleitorais, partidos e política orçamentária”. Dados, v. 45, n. 2, p. 303-344.

GLASSMAN, M.; SHOGAN, Colleen J. \&STRAUS, Jacob R. (2012). Social networking and constituent communications: member use of Twitter during a two-month period in the 111th Congress. Disponível em <http://www. fas.org/sgp/crs/misc/R41066.pdf>. Acessado em 10 out. 2012.

GOLBECK, Jennifer; GRIMES, Justin \& ROGERS, Anthony (2010). “Twitter use by U.S. Congress". Journal of the American Society for Information Science and Technology, v. 61, n. 8, p. 1612-1621. 
GOMES, Wilson (2004). Transformações da política na era da comunicação de massa. São Paulo: Paulus.

(2009). "Audioesfera política e visibilidade pública: os atores políticos no Jornal Nacional”, em GOMES, Itania M. M. (org.). Televisão e realidade. Salvador: Edufba.

GOMES, Wilson; FERNANDES, Breno; REIS, Lucas \& SILVA, Tarcizio (2009). "Politics 2.0: A campanha on-line de Barack Obama em 2008". Revista de Sociologia e Política, n. 17, p. 29-43.

GUEORGUIEVA, Vassia. (2008). "Voters, MySpace, and YouTube: the impact of alternative communication channels on the 2006 Election Cycle and Beyond”. Social Science Computer Review, v. 26, n. 3, p. 288-300.

GULATI, Girish J. \& WILLIAMS, Christine B. (2013). "Social media and campaign 2012: developments and trends for Facebook adoption”. Social Science Computer Review, n. 31, p. 577-588.

HARGITTAI, Eszter \& LITT, Eden (2012). "Becoming a tweep”. Information, Communication \& Society, v. 15, n. 5, p. 680-702.

LILLEKER, Darren G. \& JACKSON, Nigel A. (2009). "Interacting, representing or just informing: Web 2.0 and UK MP?”. Trabalho apresentado na $5^{\mathrm{a}}$ ECPR General Conference. Potsdam, 10 a 12 de setembro.

LILLEKER, Darren G. \& VEDEL, Theirry (2013). “The Internet in campaigns and elections”, em DUTTON, W. (ed.). Oxford handbook of Internet studies. Oxford: Oxford University Press.

MAIA, Rousiley Celi Moreira; GOMES, Wilson \& MARQUES, Francisco Paulo Jamil Almeida (2011). Internet e participação política no Brasil. Porto Alegre: Sulina.

MARQUES, Francisco Paulo Jamil Almeida (2008). Participação política e internet: meios e oportunidades digitais de participação civil na democracia contemporânea, com um estudo do caso do estado brasileiro. Tese (Doutorado em Comunicação e Cultura Contemporâneas) Universidade Federal da Bahia, Salvador, BA.

MARQUES Francisco Paulo Jamil Almeida; AQUINO, Jakson Alves de \& MIOLA, Edna (2014). "Parlamentares, representação política e redes sociais digitais: perfis de uso do twitter na Câmara dos Deputados". Opinião Pública, v. 20, n. 2, inédito.

MARQUES, Francisco Paulo Jamil Almeida; SAMPAIO, Rafael. Cardoso. \& AGGIO, Camilo. (orgs.) (2013). Do clique à urna: internet, redes sociais 
e eleições no Brasil. Salvador: Edufba.

MIGUEL, Luis Felipe (2010). "Os partidos brasileiros e o eixo 'esquerdadireita”, em KRAUSE, Silvana; DANTAS, Humberto; MIGUEL, Luis Felipe (orgs.). Coligações partidárias na nova democracia brasileira: perfis e tendências. São Paulo: Editora Unesp; Rio de Janeiro: Fundação Konrad Adenauer.

MIGUEL, Luis Felipe \& BIROLI, Flavia (2010). "Visibilidade na mídia e campo político no Brasil”. Dados, v. 53, n. 3, p. 695-735.

NORRIS, Pippa (2002). Digital divide: civic engagement, information poverty, and the internet worldwide. Cambrige: Cambrige University Press.

POLE, Antoinette \& XENOS, Michael (2011). "Like, comments and retweets: Facebooking and tweeting on the 2010 gubernatorial campaign trail”. Trabalho apresentado na $11^{\text {a }}$ State Politics \& Public Policy Conference. Hanover, 4 de junho.

PRESIDENTE “bomba” em Twitter inativo (2013). Estadão. São Paulo, 09 fev. Disponível em: http://politica.estadao.com.br/noticias/ eleicoes,presidente-bomba-em-twitter-inativo-imp-,994944. Acessado em 30 abr. 2014.

R CORE TEAM (2014). $R$ : a language and environment for statistical computing. Viena: R Foundation for Statistical Computing.

SMITH, Graham (2009). Democratic innovations: designing institutions for citizen participation. Cambridge: Cambridge University Press.

TAROUCO, Gabriela da Silva \& MADEIRA, Rafael Machado (2012). “Os partidos brasileiros segundo seus estudiosos: análise de um expert survey". Trabalho apresentado no XV Encontro de Ciências Sociais do Norte e Nordeste. Teresina, 4 a 7 de setembro.

TWITTER (2012). “There are now more than 200M monthly active @twitter users.”Twitter: @twitter, 18 dez. Disponível em: https://twitter.com/ twitter/status/281051652235087872. Acessado em 04 fev. 2013.

WILLIAMS, Christine B. \& GULATI, Girish J. (2010). "Communicating with constituents in 140 characters or less: Twitter and the diffusion of technology innovation in the United States Congresss". Disponível em: http://papers.ssrn.com/sol3/papers.cfm?abstract_id=1628247. Acessado em 30 abr. 2014.

WILLIAMSON, Andy (2009). “The effect of digital media on MPs' communication with constituents". Parliamentary Affairs, v. 62, n. 3, p. 514-527. 


\section{Resumo}

Resultado de uma pesquisa realizada entre os anos de 2011 e 2013, o trabalho investiga quantitativamente um conjunto de fatores relacionados à adoção do Twitter por parte dos 457 deputados federais brasileiros registrados no microblog. Com base na análise das variáveis relativas ao volume de publicação de mensagens e ao número de seguidores (monitoradas entre fevereiro de 2012 e fevereiro de 2013), confrontadas com variáveis independentes de cunho individual e político, descobriu-se, dentre outras questões, que um parlamentar relativamente jovem, com alta votação, early adopter dos media digitais e integrante de um partido de esquerda é aquele que apresenta um perfil de uso mais intenso do Twitter.

Palavras-Chave: internet; redes sociais digitais; Twitter; Congresso; política; imagem pública.

\section{Abstract}

The paper presents the results of a quantitative research undertaken between February 2012 and February 2013 on the factors related to the use of Twitter by 457 Brazilian federal deputies. We analyze the volume of messages posted and the number of followers of each deputy in order to examine how those variables relate to individual and political characteristics. Results show, among other things, that the deputy who most uses the microblog has the following profile: a relatively young user, highly voted, an early adopter of digital media and a member of a leftist party.

Keywords: Internet; social media; Twitter; Congress; politics; public image.

Recebido em 3 de julho de 2013.

Aprovado em 23 de setembro de 2013. 